\title{
Is having a sweetheart enough to survive?
}

\author{
Samia Massalha, MD, ${ }^{\mathrm{a}, \mathrm{b}}$ and Riemer H. J. A. Slart, MD, PhD ${ }^{\mathrm{c}, \mathrm{d}}$ \\ a Division of Cardiology, Department of Medicine, University of Ottawa Heart Institute, Ottawa, \\ ON, Canada \\ b Department of Cardiology, Rambam Health Care Campus, Haifa, Israel \\ c Department of Nuclear Medicine and Molecular Imaging, University Medical Center \\ Groningen, University of Groningen, Groningen, The Netherlands \\ d Department of Biomedical Photonic Imaging, TechMed Centre, University of Twente, \\ Enschede, The Netherlands
}

Received Aug 30, 2018; accepted Aug 30, 2018

doi: 10.1007/s12350-018-1435-0

See related article, pp. 269-279

Almost three decades after the description of improved left ventricular function caused by chronic impaired coronary perfusion, and the rise of the term "Hibernation," finding that hibernating myocardium is still a challenge for cardiologists.

Mortality rates among patients with ischemic cardiomyopathy remain high; the 10 -year mortality rate reaches $70 \%$ in medically treated patients and is down to $60 \%$ in the surgically treated patients. ${ }^{1}$ Despite the improvement in surgical techniques, early post-surgical mortality rates are still high and reach as high as $8 \%{ }^{1}$ Therefore, tailoring the proper medical or interventional management strategy in this group of patients is crucial.

Several studies have examined the benefit of revascularization versus medical management in patients with ischemic cardiomyopathy using viability testing prior to clinical decision making. Surgical against medical treatment studies in patients with ischemic cardiomyopathy including the STITCH trial ${ }^{2}$ and the long-term follow-up of STITCH ${ }^{1}$ did not show significant difference between the two treatment arms. STITCH however had several limitations, most importantly, viability testing based on clinician's decision

Reprint requests: Riemer H. J. A. Slart, MD, PhD, Department of Nuclear Medicine and Molecular Imaging, University Medical Center Groningen, University of Groningen, Hanzeplein 1, 9700 RB Groningen, The Netherlands; r.h.j.a.slart@umcg.nl

J Nucl Cardiol 2020;27:280-2.

$1071-3581 / \$ 34.00$

Copyright (c) 2018 American Society of Nuclear Cardiology. leading to biased results. On the other hand, PARR-2 ${ }^{3}$ and the Ottawa FIVE $^{4}$ studies showed that viability testing with FDG-PET can assist clinicians in decision making and improving patient's outcome when adhering to the scan recommendations. In addition, adherence to PET guided therapy according to amount of hibernating myocardium also led to improved quality of life. ${ }^{5}$

Viability studies are usually reserved for patients with moderate to severe left ventricular systolic dysfunction with ejection fraction $\leq 35 \%$, a viability study usually begins with the assessment of myocardial perfusion using either PET or SPECT studies. While evaluating viability, a perfusion defect in a stress/rest study that matches an area of hypocontractility indicates a viable myocardium. An area with rest perfusion defect that is not aggravated by stress usually indicates an area of either transmural or non-transmural scar or a viable myocardium, and this is where viability testing is usually indicated for instance to predict functional left ventricular recovery after revascularization. ${ }^{6}$

Abnormalities in a PET viability study are divided in four groups: (1) Viable myocardium (mismatch), normal glucose uptake corresponding to an area with either normal or reduced perfusion. (2) Non-transmural scar (match), reduced glucose uptake corresponding to a hypoperfused area. (3) Transmural scar (match), absence of myocardial glucose uptake corresponding to an area with the absence of perfusion. (4) Reverse mismatch, reduced myocardial glucose uptake in the presence of normal perfusion.

As in all fields of medicine, one considers the benefit versus risk in a treatment strategy. Many centers adapted the decision making for whether revascularization or medical treatment based on the amount of viable myocardium and extension of scar. 
Cardiac PET viability studies rely on the metabolic adaptation of myocytes to stress conditions such as ischemia. The heart is adapted to utilize various metabolic substrates and able to tightly control its substrate utilization during ischemic conditions, changes in substrate supply or according to circulating hormone levels. Under normal conditions, myocytes rely on less than $25 \%$ of its energy demand on glucose; most of the energy is derived from free fatty acid. Despite that the heart switches its metabolic demand to glucose during ischemia.

The main glucose transporters in the heart are GLUT1 and GLUT-4. The overall expression of those transporters and their relative distribution on plasma membrane determine the rate of glucose transport in the heart.

Myocardial ischemia increases GLUT-1 mRNA and protein level in both ischemic and non-ischemic regions of the heart in several animal studies. ${ }^{7,8}$ GLUT-4 secretion and translocated into the cellular membrane is stimulated by stress conditions such as ischemia and causes a net effect of an increase in the maximal velocity of glucose transport into the cell resulting in a 10-20fold increase in glucose uptake. ${ }^{9,10}$

As mentioned previously, the challenge is determining which patients are going to benefit from revascularization, whether by improving left ventricular ejection fraction, treatment of angina, reducing the risk of sudden cardiac death, and improve quality of life. So far, there is no cut off or threshold where a clinician can rely on in decision making. In this issue of the journal, KuanYin et al. took us one step closer to quantifying myocardial glucose uptake by quantifying glucose utilization using the list mode counts. ${ }^{11}$ Their results represent both the physiological and pathophysiological pathways in cell glucose uptake. While transmural and non-transmural scar areas had lower myocardial utilization rates, mismatch and reverse mismatch segments had higher glucose utilization rates, resembling the physiological glucose uptake pathway. On the other hand, studies have shown that statins do interfere in cell glucose uptake. A 30 to $40 \%$ decrease in LDL is associated with a $13 \%$ increased risk for diabetes, one proposed mechanism is the interference with the function of GLUTs. ${ }^{12-14}$ Furthermore, hyperlipidemia represented by increased levels of free fatty acids affect gene expression of GLUT4 at the level of transcription, leading to a reduced level of the transporter. ${ }^{15}$ These conflicting factors were translated in this study to actual values, showing reduction in glucose utilization in match transmural segments in patients with hyperlipidemia and in patients treated with statins.

The interesting result in the study was also the negative correlation between anti-diabetic treatment with dipeptidyl peptidase-4 inhibitors (DDP-4i) and glucose utilization. While DDP-4i is known to upregulate GLUTs and is supposedly cardioprotective ${ }^{16,17}$ and we are supposed to see an improvement in glucose utilization, results here are contradicting, especially that this trend was seen in all four patterns of glucose uptake. Whether this is attributed to the reduction in GLUT-1 in all regions and not exclusive for ischemic areas needs to be further investigated.

Following myocardial infarction, cardiac fibroblasts are activated and lead to the expansion of the extracellular matrix causing myocardial remodeling and eventually fibrosis. This might explain a lower survival probability in patients with transmural scar with increased values of myocardial glucose utility, and might be due to a continuous process of myocardial remodeling and activation of fibroblasts. While little is known about the exact mechanism and the consequences of the normal perfusion-hypo-metabolized myocardium-reverse mismatch, some studies showed that reversed mismatch represents a viable myocardium, while others indicated its association with severe disease and non-transmural infarction. ${ }^{18-21}$ The balance of myocardial metabolism is tightly regulated and depends on multiple factors including availability of nutrient, myocardial pathology, circulating hormones, and insulin resistance. Adequate shifting of myocardial metabolism from free fatty acid to glucose should be considered when interpreting a viability study, particularly in the present study and the applied protocol. The results in the current study divided patients with reverse mismatch into two groups with lower and higher glucose utilization. The group with a higher glucose utilization had a worse outcome and was also similar to the increased glucose utilization in the presence of scar probably due to the activation of myocardial fibroblasts. Whether reverse mismatch was in the septum is unknown, because that can be attributed to reduced glucose metabolism due to left bundle branch block.

Currently, management of moderate to severe ischemic cardiomyopathy is still complex. Adding the rate of myocardial glucose uptake to conventional myocardial metabolism-perfusions patterns on PET maybe helpful for better prognostic prediction of cardiovascular risks, but be aware of conflicting factors. Further research in cardiac metabolism is needed to make decision making more clinically applicable.

\section{Disclosures}

The authors have nothing to disclose.

\section{References}

1. Velazquez EJ, Lee KL, Jones RH, Al-Khalidi HR, Hill JA, Panza JA, Michler RE, Bonow RO, Doenst T, Petrie MC, Oh JK, She L, Moore VL, Desvigne-Nickens P, Sopko G, Rouleau JL. Coronary- 
artery bypass surgery in patients with ischemic cardiomyopathy. $\mathrm{N}$ Engl J Med 2016;374:1511-20.

2. Velazquez EJ, Lee KL, Deja MA, Jain A, Sopko G, Marchenko A, Ali IS, Pohost G, Gradinac S, Abraham WT, Yii M, Prabhakaran D, Szwed H, Ferrazzi P, Petrie MC, O'Connor CM, Panchavinnin P, She L, Bonow RO, Rankin GR, Jones RH, Rouleau J-L. Coronary-artery bypass surgery in patients with left ventricular dysfunction. N Engl J Med 2011;364:1607-16.

3. Mc Ardle B, Shukla T, Nichol G, Dekemp RA, Bernick J, Guo A, Lim SP, Davies RA, Haddad H, Duchesne L, Hendry P, Masters R, Ross H, Freeman M, Gulenchyn K, Racine N, Humen D, Benard F, Ruddy TD, Chow BJ, Mielniczuk L, Dasilva JN, Garrard L, Wells GA, Beanlands RSB. Long-term follow-up of outcomes with F-18-fluorodeoxyglucose positron emission tomography imaging-assisted management of patients with severe left ventricular dysfunction secondary to coronary disease. Circ Cardiovasc Imaging 2016;9:1-8.

4. Abraham A, Nichol G, Williams KA, Guo A, de Kemp RA, Garrard L, Davies RA, Duchesne L, Haddad H, Chow B, Da Silva J, Beanlands RSB. ${ }^{18}$ F-FDG PET imaging of myocardial viability in an experienced center with access to ${ }^{18} \mathrm{~F}$-FDG and integration with clinical management teams: The Ottawa-FIVE substudy of the PARR 2 trial. J Nucl Med 2010;51:567-74.

5. Dorbala S, Vangala D, Bruyere J, Quarta C, Kruger J, Padera R, Foster C, Hanley M, Di Carli MF, Falk R. Coronary microvascular dysfunction is related to abnormalities in myocardial structure and function in cardiac amyloidosis. JACC Heart Fail 2014;2:358-67.

6. Slart RHJA, Bax JJ, van Veldhuisen DJ, van der Wall EE, Irwan R, Sluiter WJ, Dierckx RA, de Boer J, Jager PL. Prediction of functional recovery after revascularization in patients with chronic ischaemic left ventricular dysfunction: head-to-head comparison between $99 \mathrm{mTc}$-sestamibi/18F-FDG DISA SPECT and $13 \mathrm{~N}$-ammonia/ 18F-FDG PET. Eur $\mathrm{J}$ Nucl Med Mol Imaging 2006;33:716-23.

7. Brosius FC, Liu Y, Nguyen N, Sun DQ, Bartlett J, Schwaiger M. Persistent myocardial ischemia increases GLUT1 glucose transporter expression in both ischemic and non-ischemic heart regions. J Mol Cell Cardiol 1997;29:1675-85.

8. Feldhaus LM, Liedtke AJ. mRNA expression of glycolytic enzymes and glucose transporter proteins in ischemic myocardium with and without reperfusion. J Mol Cell Cardiol 1998;30:247585

9. Gould GW, Holman GD. The glucose transporter family: Structure, function and tissue-specific expression. Biochem J 1993;295:329-41.

10. Bryant NJ, Govers R, James DE. Regulated transport of the glucose transporter GLUT4. Nat Rev Mol Cell Biol 2002;3:267-77.

11. Ko Kuan-Yin, Wang Shan-Ying, Yen Ruoh-Fang, Shiau YuChien, Hsu Jung-Cheng, Tsai Hao-Yuan, Lee Chien-Lin, Chiu Kuan-Ming, Yen-Wen Wu. Clinical significance of quantitative assessment of glucose utilization in patients with ischemic cardiomyopathy. J Nucl Cardiol 2018. https://doi.org/10.1007/ s12350-018-1395-4.

12. Wang S, Cai R, Yuan Y, Varghese Z, Moorhead J, Ruan XZ. Association between reductions in low-density lipoprotein cholesterol with statin therapy and the risk of new-onset diabetes: A meta-analysis. Sci Rep 2017;7:1-9.

13. Nowis D, Malenda A, Furs K, Oleszczak B, Sadowski R, Chlebowska J, Firczuk M, Bujnicki JM, Staruch AD, Zagozdzon R, Glodkowska-Mrowka E, Szablewski L, Golab J. Statins impair glucose uptake in human cells. BMJ Open Diabetes Res Care 2014;2:e00017.

14. Takaguri A, Satoh K, Itagaki M, Tokumitsu Y, Ichihara K. Effects of atorvastatin and pravastatin on signal transduction related to glucose uptake in 3T3L1 adipocytes. J Pharmacol Sci 2008;107:80-9.

15. Armoni M, Harel C, Bar-Yoseph F, Milo S, Karnieli E. Free fatty acids repress the GLUT4 gene expression in cardiac muscle via novel response elements. J Biol Chem 2005;280:34786-95.

16. Nauck MA, Meier JJ, Cavender MA, El Aziz MA, Drucker DJ. Cardiovascular actions and clinical outcomes with glucagon-like peptide-1 receptor agonists and dipeptidyl peptidase-4 inhibitors. Circulation 2017;136:849-70.

17. de Boer SA, Heerspink HJL, Lefrandt JD, de Boer MCH, van Roon AM, Juárez Orozco LE, Glaudemans AWJM, Kamphuisen PW, Slart RHJA, Mulder DJ. Effect of linagliptin on arterial ${ }^{18} \mathrm{~F}$ fluorodeoxyglucose positron emission tomography uptake: A randomized controlled trial (RELEASE). J Am Coll Cardiol 2017;69:1097-8.

18. Shirasaki H, Nakano A, Uzui H, Yonekura Y, Okazawa H, Ueda $\mathrm{T}$, Lee JD. Comparative assessment of ${ }^{18} \mathrm{~F}$-fluorodeoxyglucose PET and 99mTc-tetrofosmin SPECT for the prediction of functional recovery in patients with reperfused acute myocardial infarction. Eur J Nucl Med Mol Imaging 2006;33:879-86.

19. Anselm DD, Anselm AH, Renaud J, Atkins HL, De Kemp R, Burwash IG, Williams KA, Guo A, Kelly C, Dasilva J, Beanlands RSB, Glover CA. Altered myocardial glucose utilization and the reverse mismatch pattern on rubidium-82 perfusion/F-18-FDG PET during the sub-acute phase following reperfusion of acute anterior myocardial infarction. J Nucl Cardiol 2011;18:657-67.

20. Yamagishi H, Akioka K, Hirata K, Sakanoue Y, Takeuchi K, Yoshikawa J, Ochi H. A reverse flow-metabolism mismatch pattern on PET is related to multivessel disease in patients with acute myocardial infarction. J Nucl Med 1999;40:1492-8.

21. Hansen AK, Gejl M, Bouchelouche K, Tolbod LP, Gormsen LC. Reverse mismatch pattern in cardiac ${ }^{18} \mathrm{~F}$-FDG viability PET/CT is not associated with poor outcome of revascularization: A retrospective outcome study of 91 patients with heart failure. Clin Nucl Med 2016;41:e428-35. 